\title{
After the Flood
}

\section{Anger, Attribution, and the Seeking of Information}

\author{
Robert J. Griffin \\ Marquette University, Milwaukee, Wisconsin \\ Zheng Yang \\ Cornell University, Ithaca, New York \\ Ellen ter Huurne \\ University of Twente, Enschede, The Netherlands \\ Francesca Boerner \\ Research Center Juelich, Germany \\ Sherry Ortiz \\ Marquette University, Milwaukee, Wisconsin \\ Sharon Dunwoody \\ University of Wisconsin-Madison
}

\begin{abstract}
In an effort to understand what motivates people to attend to information about flood risks, this study applies the Risk Information Seeking and Processing model to explore how local residents responded to damaging river flooding in the Milwaukee area. The results indicate that anger at managing agencies was associated with the desire for information and active information seeking and processing, as well as with greater risk judgment of harm from future flooding, greater sense of personal efficacy, lower institutional trust, and causal attributions for flood losses as being due to poor government management.
\end{abstract}

Keywords: risk communication; risk perception; information seeking; information processing; attribution theory; anger; flooding

\footnotetext{
Authors' Note: Data were gathered under a Science to Achieve Results (S.T.A.R.) Watershed Program grant (USEPA R82-5759) to Marquette University from the U.S. Environmental Protection Agency in conjunction with the National Science Foundation and U.S. Department of Agriculture. This report represents the views of the authors of this paper and not necessarily the views of these agencies. The authors thank Vladimir Novotny, principal investigator (now at Northeastern University), and David Clark (Marquette University) for their contributions to this project and this journal's anonymous reviewers for their very useful guidance toward improving the manuscript. Address inquiries to Robert J. Griffin, Diederich College of Communication, Marquette University, P.O. Box 1881, Milwaukee, WI 53201; phone: (414) 288-6787; e-mail: Robert.Griffin@ Marquette.edu.
} 


\section{L}

arge-scale natural disasters, such as the flooding damage inflicted by Hurricane Katrina on New Orleans in 2005, can command the national spotlight. In their wake, media attention often focuses on what could have been done to limit the damage and loss of life, what should be done to limit the risk of harm from similar events in the future, and which individuals or agencies are responsible and perhaps blameworthy. Even people not personally affected by the disaster can direct anger at public officials and agencies seen as being at fault for bad outcomes that could have been prevented.

Under such conditions, communication about risk is not limited to attempts by experts to provide public education to individuals about their personal health or safety. Instead, risk communication often becomes debate over a public issue, typically involving political actors and the public trust (Laird, 1989; McComas, 2004). People may seek information about the issue not because they are immediately fearful for their own health, but because they are angry and watchful of public stewards who, if they behave in untrustworthy ways, send signals that they may well fail citizens in future events.

Even smaller scale floods or other disasters which are more common than Katrina's damage to New Orleans can have similar impacts on local communities, involving local agencies and media. This study examines one such instance, the aftermath of repeated flooding of an urban river, in this case, one that flows through a major city in the Great Lakes region of the United States.

To the task of understanding what motivates local residents to attend to information about the flooding, even if they are not themselves in harm's way, we apply the model of Risk Information Seeking and Processing (RISP) (Griffin, Dunwoody, \& Neuwirth, 1999). The model proposes that emotions can motivate more active information seeking and processing. Past tests of the model (Griffin, Neuwirth, Dunwoody, \& Giese, 2004) have emphasized the impacts of worry about one's health. This study will expand our understanding of the role of emotion in seeking and processing by testing the model in the context of another emotion: anger. Local residents might feel anger toward agencies entrusted to protect the community from flooding. This study will also examine some of the factors, such as perceived risk and attributions for the causes of the flooding, which might provoke such anger. It also further tests the RISP model in the area of impersonal risk (Kahlor, Dunwoody, Griffin, \& Neuwirth, 2006), that is, risks to entities other than the self.

\section{Flooding Issue Background}

As an area becomes more urban and less rural, it produces increased runoff; that is, more of the rain that falls on the land runs into streams and 
rivers instead of soaking into the ground. Over time, the kind of flooding that damages people's homes becomes more frequent and the size of the area that is flooded expands so homes that are not currently at risk of flooding could face risks in the future (Novotny, Clark, Griffin, \& Booth, 2000). In urban areas, flooding can be a social, economic, and environmental issue for residents of the entire watershed - and not just of the floodplain (i.e., the area around the river that can become flooded) - because upstream development can produce downstream hardship, often among those less well off.

In the late 1990s, flooding became a salient issue in the Menomonee River region of the greater Milwaukee area in Wisconsin. The 137-square-mile watershed of the Menomonee River begins in a wetland northwest of the city, flows through developing and developed suburban areas, and then through the lower income and industrial heart of the central city, where it eventually empties into Lake Michigan after a run of 28 miles. More than a third of a million people live in the Menomonee River watershed, about $85 \%$ of them in urban areas. In 1997 and again in 1998, amidst some smaller floods, two large (so-called "100-year") floods affected downstream residents, causing millions of dollars in property damage and loss of homes. (A "100-year" flood is one that is so large that the odds of it happening in a given year are about $1 \%$.) During subsequent years, considerable public controversy and media coverage focused on who or what was at fault and what steps were needed to alleviate flooding problems. ${ }^{1}$

\section{Applying the RISP Model}

We employ the RISP model (Griffin, Dunwoody, \& Neuwirth, 1999) to examine the processes which may have affected local residents' attention to information about the flood risk after the 1997 and 1998 floods. The RISP model, illustrated in Figure 1, is based on Eagly and Chaiken's (1993) Heuristic-Systematic Model (HSM), which describes dual forms of human processing of information. Heuristic processing is comparatively superficial and limited and requires fewer cognitive resources. People usually employ heuristic processing as the default, allowing them to conserve their informationseeking and processing resources. When employing heuristic processing, people tend to judge the validity of messages based on superficial cues, such as the length of the message or the use of a trusted spokesperson. Systematic processing is a much more comprehensive effort to analyze and understand the information. Systematic processing can produce more stable attitudes and beliefs (Eagly \& Chaiken, 1993) and has been associated with more strongly held beliefs related to a risk (Griffin, Neuwirth, Giese, \& Dunwoody, 2002). 


\section{Figure 1}

Model of Risk Information Seeking and Processing (based on Griffin, Dunwoody, \& Neuwirth, 1999)

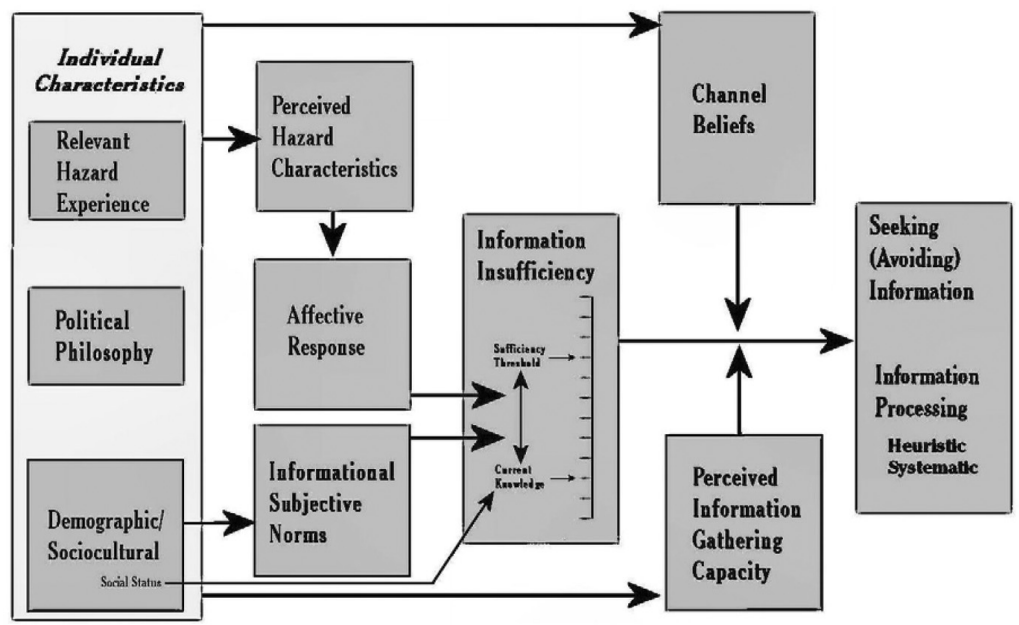

In HSM terms, people tend to adopt the form of processing that they use for a given message based on (1) their capacity to process the information in each manner, and (2) their motivation to go beyond the more superficial (heuristic) processing to engage in systematic processing. Heuristic and systematic processing are separate processing strategies that can co-occur. In fact, recent research (Dijksterhuis, Bos, Nordgren, \& Van Baaren, 2006) suggests that a combination of systematic and heuristic processing may produce better decisions than will systematic processing alone.

According to the HSM formulation, a person's desire for sufficiency motivates systematic processing. Eagly and Chaiken (1993) observe that "people will exert whatever effort is required to attain a 'sufficient' degree of confidence that they have accomplished their processing goals" (p. 330). For example, the personal relevance of the message topic to the individual elevates the amount of judgmental confidence people need to have (the "sufficiency threshold") in their own attitudes (e.g., Do their attitudes square with relevant facts? Are they defensible? Are they socially acceptable?) and/or the confidence they need to have in the validity of the message (Eagly \& Chaiken, 1993). 


\section{Key Model Components}

Information insufficiency. Griffin, Dunwoody, and Neuwirth (1999) propose that the drive to overcome information insufficiency (e.g., to gain and hold enough information to feel confident in an attitude or to deal with a risk in daily life) motivates individuals to process risk-related information more systematically and less heuristically. They also propose, based on Eagly and Chaiken's (1993) motivational factor, that the sufficiency drive (i.e., the size of the gap between information held and needed) will ultimately affect the information-seeking and processing styles employed by individuals to learn more about the risk. This information insufficiency can similarly motivate people to do more active, nonroutine seeking of information, for example, to go beyond their habitual sources of information, such as television news, to search actively for information on the Internet.

However, information seeking and processing are also seen as dependent upon one's ability to learn more about the risk (based on HSM's concept of capacity), one's existing knowledge structures, and the perceived usefulness of available information. Therefore, seeking and processing are also affected by the variables termed "perceived information gathering capacity" and "relevant channel beliefs" in the RISP model.

Perceived information gathering capacity. Because risk information seeking and processing are essentially communication behaviors, one's sense of self-efficacy (Bandura, 1986) or perceived behavioral control (Ajzen, 1988) in performing them are important to measure. Informationgathering capacity reflects an individual's perceived ability to perform the information seeking and processing steps necessary for the outcome he or she desires, especially when an outcome requires more cognitive effort and nonroutine gathering of information. Although not specified in the model, current knowledge of the risk could enhance an individual's capacity to gather new knowledge about it. For example, knowledge gap researchers have noted that existing knowledge would provide individuals a "trained capacity" to gain access to additional information (Griffin, 1990; Viswanath \& Finnegan, 1995, p. 200; Kahlor et al., 2006).

Previous analyses based on the RISP model have found support for a relationship between more effortful information seeking and processing and information sufficiency motivation (Griffin, Neuwirth, \& Dunwoody, 1998; Trumbo, 2002; Kahlor, Dunwoody, Griffin, Neuwirth, \& Giese, 2003; Griffin, Powell, et al., 2004; Griffin et al., 2005; Kahlor et al., 2006) and capacity (Griffin, Powell, et al., 2004; Griffin et al., 2005). 
Channel beliefs. Beliefs that individuals have about channels of risk information could affect the information-seeking and processing strategies people employ. Two channel belief factors have emerged thus far from various analyses done of the RISP model, both dealing primarily with mass media: the belief that media distort reality and the belief that the media provide useful cues for processing the information (Griffin, Powell, et al., 2004). Most work with channel beliefs in the RISP model remains exploratory.

Informational subjective norms. Based on Ajzen (1988), the RISP model proposes that informational subjective norms, that is, felt pressures from relevant others to keep on top of risk information, can affect a person's desire for information (i.e., produce a sense of information insufficiency). Informational subjective norms have been found to relate positively to information insufficiency, as the model suggests, but they have also been found to have a direct, positive relationship with more active information seeking and processing (Griffin et al., 2005; Kahlor et al., 2006). This result suggests that an adjustment may be needed in the model to accommodate the role of informational subjective norms as a more direct motivational force independent of the cognitive motivation of information insufficiency.

Affective response: Anger. The RISP model proposes that affective responses such as worry or anger, or even positive responses such as hope, could also influence a person's sense of information insufficiency about the risk. This study examines whether anger at managing agencies is related to the drive for information sufficiency and, possibly, risk information seeking and processing as well.

Anger, sometimes defined as an attempt to reassert control over a situation (Frijda, 1986; Griffin, Neuwirth, et al., 2004), is more likely to develop in an individual when another person, or institution, is very much in control. ${ }^{2}$ That is, people will typically feel angry if they perceive that someone else is responsible for a negative situation (Dunn \& Schweitzer, 2005; Weiner, 2000). Based on appraisal theory (Lazarus \& Smith, 1988; Smith \& Lazarus, 1990), the core relational theme for anger is the tendency to blame others or hold others accountable. That is to say, waiting for an action in vain is likely to provoke anger, as can feeling manipulated or deceived (Lazarus, 2006). Anger may also increase the likelihood of engaging in social activism (Weiner, 2000). Thus, angry people might be motivated to gather further information in order to validate their cognitions and attitudes toward a blameworthy party (which includes preparing for arguments with others) or possibly to find ways to assert at least some control individually or in concert with others. 
Perceived hazard characteristics. The RISP model proposes that affective responses result from risk perceptions, referred to formally as perceived hazard characteristics. ${ }^{3}$ While there may be many elements to risk perception (Slovic, 1992; Gregory \& Mendelsohn, 1993), three key elements used in the RISP model to date have been risk judgment, personal efficacy, and institutional trust. In this study, we are also investigating whether attributions (perceived causes) for past flood damage play a role in how people respond affectively to the risk, in this case, whether attributions are related systematically to anger. If so, then attributions might be worth investigating further as a potential addition to the stable of perceived hazard characteristics.

Risk judgment includes an individual's estimate of the likelihood of harm to self, others, or the environment based on a given hazard (such as flooding) and his or her perception of the potential severity of that harm. Personal efficacy is the sense that a person has that he or she can do something to protect the self, others, or the environment from the harm. Its counterpart is institutional trust, the willingness to rely for protection on those who have the responsibility for making decisions and taking actions related to the management of technology, the environment, or other realms of public health and safety (Siegrist, Cvetkovich, \& Roth, 2000). Most people do not possess sufficient knowledge of science and technology to be capable of judging risks and benefits (Gregory \& Miller, 1998). People therefore have to rely on information provided by experts (Earle \& Cvetkovich, 1995), which makes them subject to their assessments and judgments. Trust in experts and government agencies to protect people from risks is especially important in cases where it concerns risks, like flood risks, that are difficult for the general public to control or understand. Building and maintaining trust, however, depends heavily on the performance of the social institutions involved (Kasperson, Golding, \& Tuler, 1992). Lack of trust can amplify the amount of risk a person perceives (Groothuis \& Miller, 1997).

Attribution theory depicts people as being informal causal theorists, attempting to determine the causes for the outcomes that they or others experience (Nisbett, Borgida, Crandall, \& Reed, 1976). Attribution research typically categorizes perceived causes as either internal (stemming from factors such as an individual's own efforts, attitude, or personality) or external (stemming from forces outside the individual). A common finding is that individuals tend to attribute their own good outcomes internally (e.g., "I worked hard") and others' good outcomes externally (e.g., "they got special treatment from others"), whereas they attribute their own bad outcomes externally and others' bad outcomes internally. Luck, however, may vary in attribution, sometimes 
being perceived as an external cause and at other times, as an internal cause (Weiner, 1983). According to McGuire (1974), "how one responds to a favorable or unfavorable outcome to oneself or to another depends on whether one attributes this outcome to an internal or external force" (p. 175). Thus, responses-affective or otherwise- that people make to a hazard such as flood damage may depend on what they see as causing the damage to occur.

In their application of attribution theory to perceived risk, Kahlor, Dunwoody, and Griffin (2002) found that individuals attributed their illness from a waterborne parasite to external causes, but their ability to avoid the illness to internal causes. This study further extends this type of analysis by including attributions for the outcomes (here, flood damage) that affected others and by associating the attributions with an affective response, anger at managing agencies.

Individual characteristics. The full RISP model in Figure 1 also includes a role for sociodemographic variables and other individual characteristics (e.g., political philosophy and past experience with a hazard) in the deep background of risk information seeking and processing. This analysis will examine the role of some of these predictors but will emphasize education, because of the positive relationship past studies have often shown between education (as indicative of social status) and differential gain in knowledge of public issues, in part due to enhanced capacity to access, process, and store that information (Tichenor, Donohue, \& Olien, 1970; Griffin, 1990).

\section{Research Questions and Hypotheses}

Our research questions and hypotheses represent the relationships among selected components of the RISP model, emphasizing the role of anger at managing agencies as a focal point. Starting, however, with processes more closely associated with individuals' communication activities, we ask:

RQ1: What are the relationships between individuals' seeking and processing of flood risk information and their immediate predictors from the RISP model (information insufficiency, perceived information gathering capacity, and channel beliefs)?

The roles that channel beliefs play in information seeking and processing (in particular, whether the relationships would be positive or negative) 
are still exploratory. However, based on Eagly and Chaiken's (1993) research and past findings from the RISP model, we have generated six directional hypotheses about information insufficiency and capacity. We expect that information insufficiency will be:

H1a: Positively related to information seeking;

$H 1 b$ : Positively related to systematic processing;

H1c: Negatively related to heuristic processing.

Further, capacity will be:

$H 1 d$ : Positively related to information seeking;

H1e: Positively related to systematic processing;

HIf: Negatively related to heuristic processing.

Although these relationships have been examined before (Griffin, Powell, et al., 2004), they will be subjected to a wider set of control variables in this analysis.

According to the RISP model, informational subjective norms and affective response (in this study, anger) will affect information insufficiency. However, recent research indicates that informational subjective norms might relate more directly to information seeking and processing as well (Griffin et al., 2005; Kahlor et al., 2006). The same might even be true of affective responses such as anger, since informational subjective norms and anger might be motivations that at times work independently of information insufficiency, a cognitively based motivator. Therefore:

$R Q 2$ : What is the relationship of information insufficiency with anger and with informational subjective norms? Specifically:

$H 2 a$ : Informational subjective norms will be positively associated with information insufficiency.

$H 2 b$ : Anger will be positively associated with information insufficiency.

RQ3: What are the relationships that anger and informational subjective norms have with individuals' seeking and processing of flood risk information?

The RISP model proposes that, in general, individual characteristics can affect perceived hazard characteristics, and various components of the latter can result in affective responses (here, anger at managing agencies), as illustrated in Figure 2. Outside of this general pattern, most specifics in regard to relationships among these variables are still exploratory and thus will be examined via research questions without directional hypotheses. This study in 


\section{Figure 2}

Detail of Perceived Hazard Characteristics

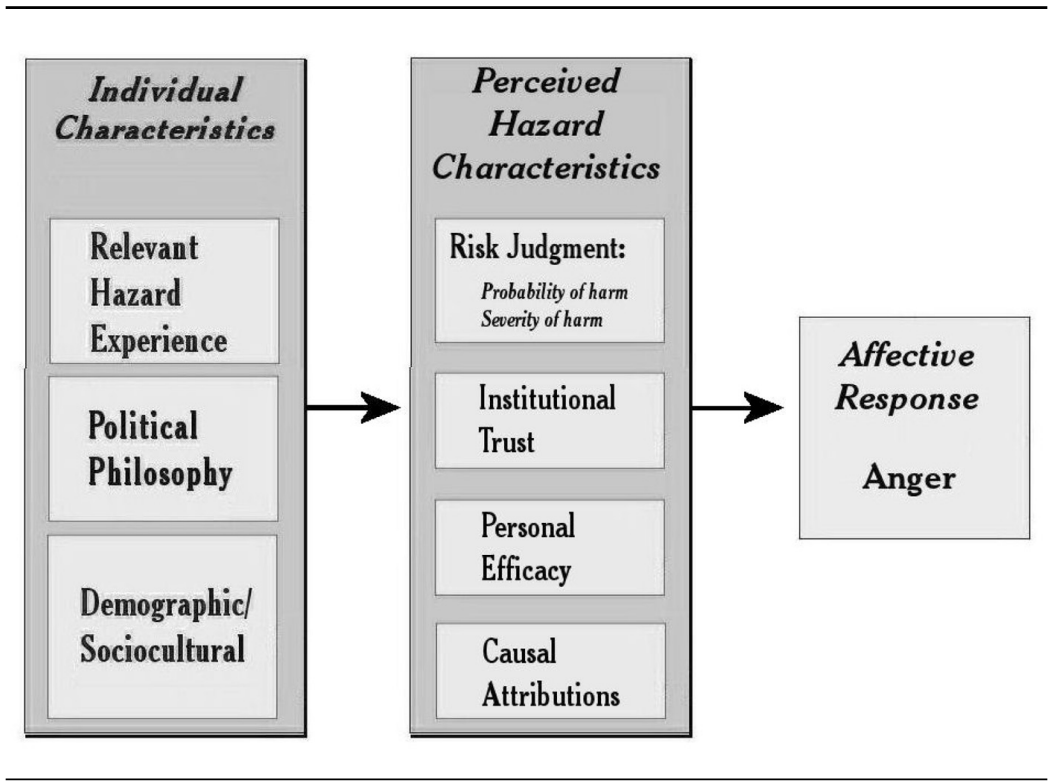

particular explores the potential roles of causal attributions (in this case, the perceived causes of the river flood damage) as a component of perceived hazard characteristics. Thus, the last set of research questions is:

RQ4: What relationships does anger have with the components of perceived hazard characteristics, in particular causal attributions for flooding losses, and with individual characteristics?

RQ5: What relationships do causal attributions for flooding losses have with the other components of perceived hazard characteristics and with individual characteristics?

\section{Method}

The data in this analysis are from the "Watershed Study," a multidisciplinary project that included a two-wave, panel-design, sample survey into public use of risk information about flooding and environmental risks related to urban rivers and their watersheds. The research project was conducted in the Milwaukee area and supported by a Science to Achieve 
Results (STAR) grant from the U.S. Environmental Protection Agency, National Science Foundation, and U.S. Department of Agriculture. The population sampled for the flood risk communication component of the survey is made up of adult residents who live in the watershed of the Menomonee River in the Milwaukee area. The Menomonee River watershed contains an ethnically and socioeconomically diverse population.

\section{Sampling and Interviewing}

From October 1999 to April 2000, the University of Wisconsin Survey Center, a professional research organization associated with the University of Wisconsin-Madison, conducted a probability sample survey by telephone of adult heads of households living in the Menomonee River watershed. Again, over the winter of 2000-2001, most respondents from the previous wave of interviews were re-interviewed, and an additional set of randomly selected respondents was added as a control for sensitization in the panel design. Respondents were chosen randomly from among the heads of households in each contacted residence and were randomly assigned to one of three paths of questioning: flood risks from the river, ecological risks to the river, or an abbreviated interview combining elements of both. Data from the full interviews about flood risks are the focus of this report.

To maximize the sample size for this analysis, we are using data from all of the first-wave respondents who were interviewed about flooding $(n=$ 303 , response rate of $48 \%$ ) and only the newly interviewed respondents from the second wave who were asked about flooding $(n=98$, response rate of $46 \%$ ), for a total sample of $N=401$. The analysis will control for when the respondent was interviewed. Interviews averaged approximately 20 minutes apiece and were verified by random callbacks. As many as 20 attempts were made to interview a given respondent. Applicable human subjects and informed consent practices were followed throughout.

\section{Measurement}

A series of focus groups that preceded the first wave of surveys guided the construction of the measures. Throughout the questionnaire, when respondents were presented with a series of items to be answered on the same kind of scale (e.g., five-point, Likert-type, agreement scale), the starting item in the list was chosen randomly. Specific measures for the RISP model concepts below are shown in the Appendix. 


\section{Table 1 \\ Correlation of Information Seeking and Processing Measures With Attention (partial correlation coefficients)}

\begin{tabular}{lcccc}
\hline & \multicolumn{5}{c}{$\begin{array}{c}\text { Self-reported attention paid to information } \\
\text { about the river flooding in: }\end{array}$} \\
\cline { 2 - 5 } & $\begin{array}{c}\text { TV } \\
\text { News }\end{array}$ & Newspaper & $\begin{array}{r}\text { Radio } \\
\text { News }\end{array}$ & Conversations \\
\hline $\begin{array}{l}\text { Information seeking about flooding } \\
\text { Processing of information about flood }\end{array}$ & .52 & .54 & .42 & .33 \\
$\quad \begin{array}{l}\text { Systematic } \\
\text { Heuristic }\end{array}$ & .40 & .48 & .40 & .25 \\
\hline
\end{tabular}

Note: $N=401$. All coefficients significant at $p \leq .001$. Coefficients are controlled by amount of exposure to news or information about the river flooding in the given medium. Respondents who are not exposed to medium had been coded as lowest value on attention scale.

Information seeking. Information seeking was measured by five items used previously in tests of the RISP model. In this analysis, items representing avoidance were reverse-coded and combined with seeking measures into a single index (alpha $=.75$ ) based on unidimensional factor analysis results (Griffin, Powell, et al., 2004).

Information processing. Eight information processing items were used, four measuring systematic processing and four heuristic processing. Weighted factor scores, based on oblique rotation, were utilized to construct indices of systematic processing (omega $=.61$ ) and of heuristic processing (omega $=$ .56). The factor score weights were derived from a pool of observations from all Watershed survey respondents (Griffin, Powell, et al., 2004).

To help validate the seeking and processing scales, we correlated them with other measures in the survey of self-reports of attention to information about Menomonee River flooding, as shown in Table 1. The results are consistent with the meanings of the seeking and processing measures.

Information insufficiency. Information insufficiency was measured by two self-report variables: (1) current knowledge about the risk and (2) the information sufficiency threshold. Rather than using the difference between current knowledge scores and sufficiency threshold scores to represent information insufficiency, this variable was assessed by regressing sufficiency threshold 
scores on current knowledge scores (Cohen \& Cohen, 1983). The term "information insufficiency" will be used to refer to a person's perception that he or she needs more information to deal with the risk, that is, that his or her current knowledge is less than sufficient.

Perceived information gathering capacity. Using Likert-type scales, six items were used to form an index (alpha $=.66)$ of respondents' beliefs about their ability to get and understand more information about Menomonee River flooding, if they wanted it.

Channel beliefs. The six items represented beliefs that the media distort information, especially through bias and sensationalism (omega $=.69$ ), and that the media provide audiences with cues about the validity of the information they contain (omega $=.41$ ) ${ }^{4}$ The factor score weights used in the analysis were derived from the pool of observations from all Watershed survey respondents.

Informational subjective norms. Respondents indicated whether they felt others important to them think they should stay on top of information about Menomonee River flooding.

Affective response: Anger. Respondents were asked to indicate on a 0-10 scale how much anger they felt that managing agencies had not done more to minimize flood risks. Anger was among a set of four possible emotions posed to respondents.

Perceived hazard characteristics. Among the set of variables in the perceived hazard characteristics set was a measure of personal efficacy in dealing with the effects of flooding. To help validate the anger and the efficacy measures, we correlated them with a set of measures elsewhere in the survey questionnaire which measured respondents' intentions to take various actions in the public sphere in response to the flood risk (i.e., responses available to individuals regardless of whether or not they lived in the flood plain), as shown in Table 2. Consistent with Weiner's (2000) assertion that anger leads to social activism, anger correlated positively with intentions to give time or money to a citizen's organization concerned about the flooding, contact government officials about the matter, attend a public meeting about it, and even vote for flood control legislation. Efficacy correlated positively with all of these measures except for the last. 
Table 2

\section{Relationship of Efficacy and Anger to Behavioral Intentions in Regard to River Flooding (Pearson product-moment correlations)}

\begin{tabular}{lcccc}
\hline \multicolumn{3}{c}{ Behavioral Intention: I would be very likely to.... } \\
\cline { 2 - 5 } & $\begin{array}{c}\text { Give time or } \\
\text { money to } \\
\text { a citizen } \\
\text { organization } \\
\text { concerned } \\
\text { about the matter }\end{array}$ & $\begin{array}{c}\text { Contact } \\
\text { government } \\
\text { officials } \\
\text { about the } \\
\text { matter }\end{array}$ & $\begin{array}{c}\text { Attend a } \\
\text { public } \\
\text { meeting } \\
\text { about the } \\
\text { matter }\end{array}$ & $\begin{array}{r}\text { Vote in favor } \\
\text { of legislation } \\
\text { designed to } \\
\text { hold the line } \\
\text { on flooding } \\
\text { of the river }\end{array}$ \\
\hline $\begin{array}{l}\text { Efficacy } \\
\text { Anger }\end{array}$ & $.19^{* *}$ & $.21^{* *}$ & $.24^{* *}$ & $.09 n s$ \\
\hline
\end{tabular}

Note: $N=401 ; n s=$ nonsignificant. The behavioral intention items were preceded by the following poser: The following are statements that people have made about things they might do that could affect the flooding of the Menomonee River and its effect on homes and properties. Not everyone can or wants to do these things. For each statement, please tell me whether you strongly agree, agree, feel neutral, disagree, or strongly disagree. I would be very likely to.... $* p \leq .01 ; * * \leq .001$.

Other components of the perceived hazard characteristics set are trust in agencies that manage flooding, risk judgment, and the possible addition of attributions for the harm that came from flooding. The trust index was composed of three measures $($ alpha $=.58)$. Risk judgment was calculated by multiplying measures of perceived likelihood of damaging flooding in the next year times perceived severity of the harm the flooding would do. Attribution was measured with a set of items representing internal attribution for the damage sustained from the flooding of the Menomonee River (people living near river seen as being responsible for their own losses) and a variety of external attributions, each incrementally more remote from those affected by the flood (poor management by government agencies, urban development upstream, and global warming). Bad luck was also included.

Demographic/sociocultural and study characteristics variables. Various demographic variables were used in this study, mostly as control variables. Based on Griffin, Dunwoody, and Neuwirth (1999), these included education (measured as educational achievement ranging from grade school to postgraduate) as well as annual household income, age, ethnicity (whether the 
person is a member of a minority group), gender, and political philosophy (liberalism or conservatism). Consistent with the topic of this study, we also included a measure of how far upstream from the mouth of the river the respondent lives and a self-report of whether he or she lives in the floodplain. (Only 12\% of respondents reported that they lived in the floodplain.) Relevant hazard experience was measured by asking whether the individual had ever suffered loss from flooding. The results were also controlled by the year in which the respondent was interviewed (1999 in Wave 1 or 2000 in Wave 2).

\section{Analysis}

The data were analyzed using the Statistical Package for the Social Sciences (SPSS), in particular by hierarchical multiple regression. To examine RQ1-RQ3 and test the related hypotheses, each of the five dependent variables (information seeking, systematic processing, heuristic processing, capacity, and information insufficiency) was regressed on the following blocks of variables in an order informed by the RISP model: (1) the set of demographic/ sociocultural and study characteristics control variables, minus education; (2) the set of perceived hazard characteristics control variables; (3) education; (4) informational subjective norms; (5) anger at local agencies; (6) the two channel beliefs factors; (7) perceived information gathering capacity; (8) current knowledge; and (9) information sufficiency threshold. Consistent with a regression approach to examining "difference" scores (Cohen \& Cohen, 1983), current knowledge was entered in the block prior to information sufficiency so that the latter variable effectively represented the difference ("information insufficiency") between current knowledge and sufficiency threshold. Where information insufficiency (the "threshold" measure) was dependent, current knowledge was entered as the first block so remaining variables predict the variance in the threshold not accounted for by current knowledge (effectively the "difference," without using difference scores). To streamline the presentation of these analyses, only the variances accounted for by the two blocks of control variables will be reported.

To examine RQ4 and RQ5, dependent variables were regressed on the following blocks of variables: (1) the set of demographic/sociocultural and study characteristics variables; (2) the set of perceived hazard characteristics variables; and (3) causal attributions. The low reliabilities of some scales may result in underestimating some relationships. 


\section{Results}

The first set of research questions concerned the precursors of risk information seeking and processing, based on the RISP model. The first research question (RQ1) concerned the relationships that information insufficiency, perceived information gathering capacity, and channel beliefs had with seeking and processing risk information.

As shown in Table 3, information insufficiency relates positively with information seeking (beta $=.18, p \leq .001$, in support of H1a) and systematic processing (beta $=.24, p \leq .001$, in support of $\mathrm{H} 1 \mathrm{~b}$ ) and negatively with heuristic processing (beta $=-.22, p \leq .001$, in support of H1c). Similarly, capacity has positive relationships with information seeking (beta $=.19$, $p \leq .001$, in support of H1d) and systematic processing (beta $=.14, p \leq .01$, in support of H1e) and a negative relationship with heuristic processing (beta $=-.11, p \leq .05$, in support of H1f). Thus, consistent with the RISP model, individuals who believe they have a deficit of knowledge about the river flooding and those who self-report greater capacity to get the information seem to devote more effort to seeking and processing it. Channel beliefs, however, offer a less consistent pattern and are not associated with seeking the risk information, only with its processing. Those who believe that media provide cues to the validity of the message are more likely to process systematically. Those who believe that the media distort the information are more likely to process heuristically. The former is fairly consistent with expectations from the RISP model, but the implications of the latter are not clear.

It is noteworthy that perceived information gathering capacity bears a positive relationship with current knowledge (beta $=.19, p \leq .001$ ). This finding, while not explicit in the model, is consistent with the idea that knowledge already learned can help individuals gain new knowledge by increasing their capacity to do so. (Of course, the opposite direction of influence for that relationship is also possible.) Capacity is also related positively to education (beta $=.14, p \leq .01$ ), a finding that is consistent with the proposed relationship in the RISP model between individual characteristics and capacity. Even without inclusion of the education variable or the wave of interviews, the control block of individual characteristics accounts for an additional $15 \%$ of the variance in capacity. This result is also consistent with the model.

Stepping back in the model to examine some of the factors that could produce a drive for more information about the flood risk, the second research question (RQ2) concerned the relationships of information sufficiency with 


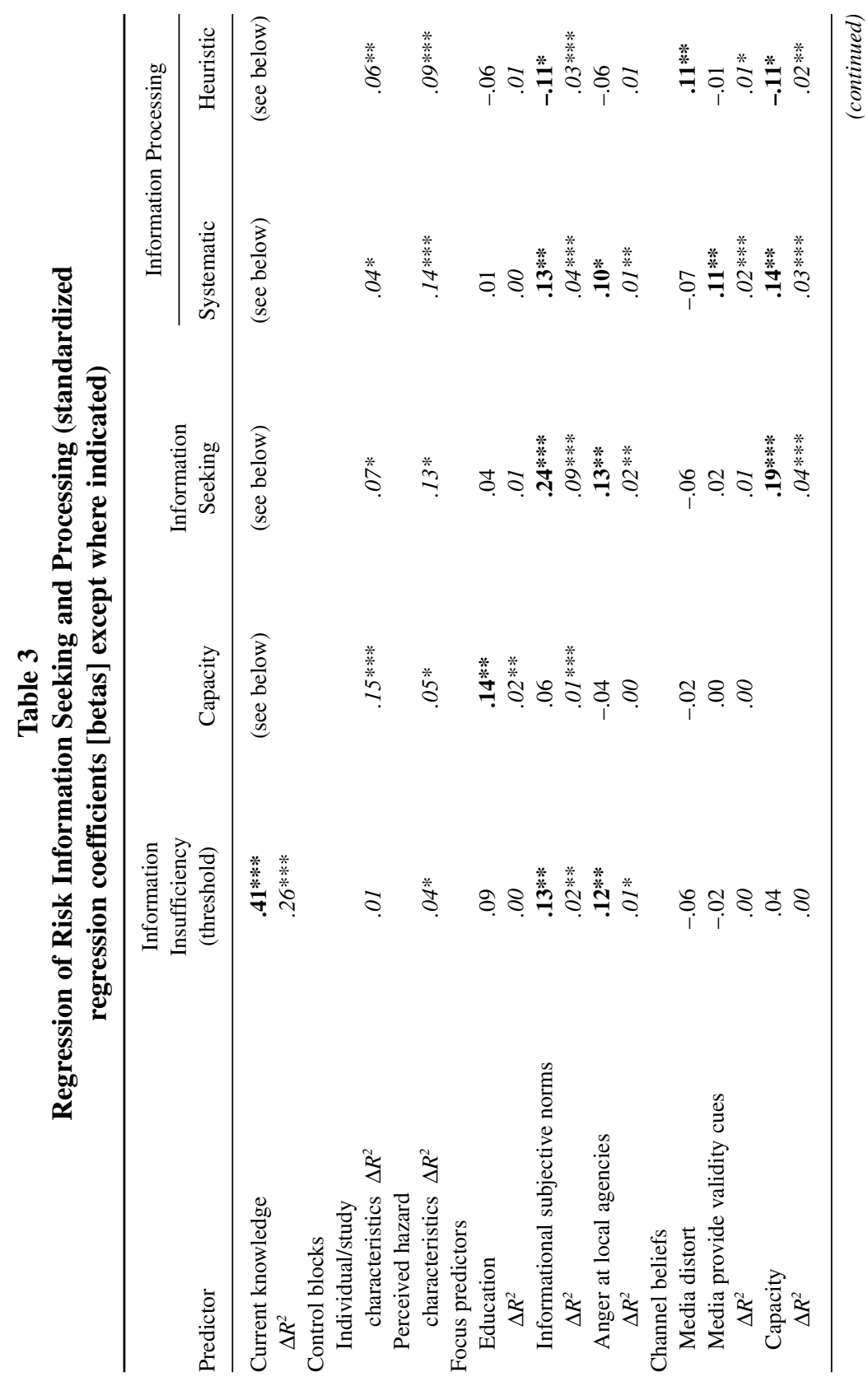




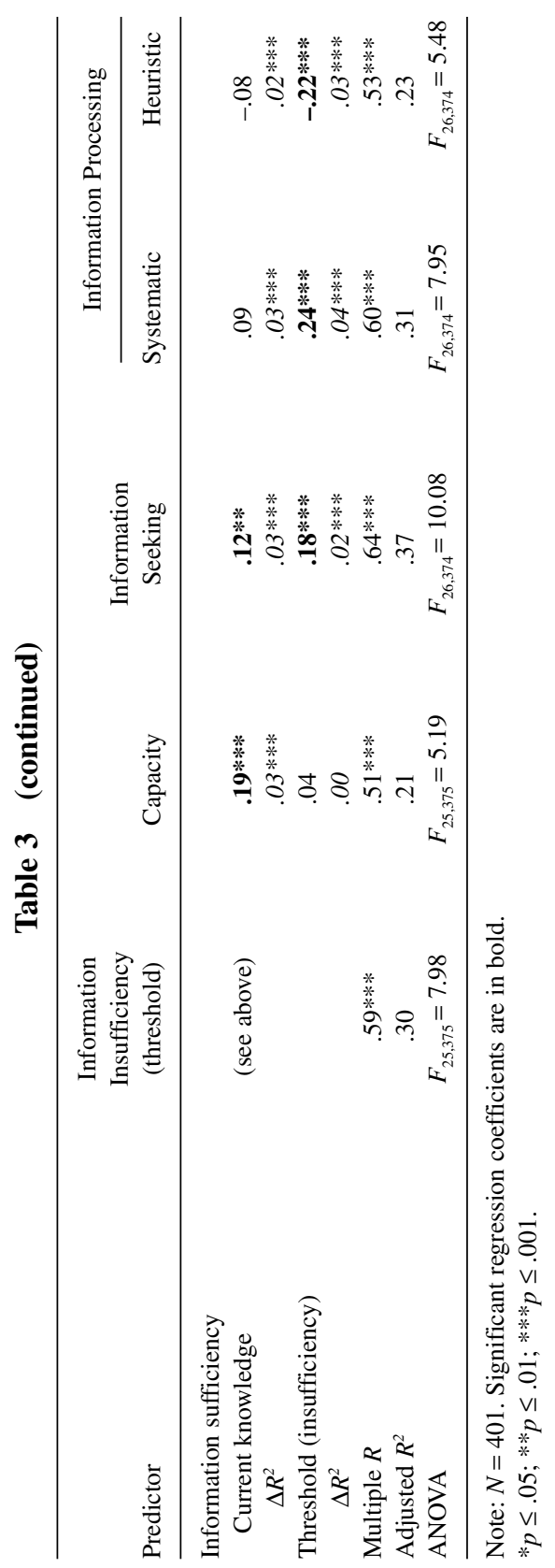


informational subjective norms and with anger toward management agencies. Table 3 shows comparatively small but positive relationships between information insufficiency and both informational subjective norms (beta $=.13, p \leq .01$, in support of H2a) and anger (beta $=.12, p \leq .01$, in support of $\mathrm{H} 2 \mathrm{~b}$ ). These results are consistent with the RISP model. By posing the third research question (RQ3), however, we wondered whether informational subjective norms and anger might have a direct relationship with the seeking and processing of risk information as well. Results show that informational subjective norms do indeed relate positively to systematic processing (beta $=.13, p \leq .01$ ) and negatively to heuristic processing (beta $=-.11, p \leq .05$ ). They also relate positively, and somewhat more strongly, to information seeking (beta $=.24, p \leq .001$ ). Anger, too, has a more direct, positive relationship with information seeking (beta $=.13, p \leq .01)$ and systematic processing (beta $=.10, p \leq .05$ ), but not with heuristic processing (beta $=-.06, n s$ ). Thus, it appears that informational subjective norms and the affective response of anger may drive the seeking and processing of risk information in indirect ways (by motivating a cognitive need for more information, as proposed by the RISP model), as well as by playing the role of being more direct motivators.

The final pair of research questions concerned the relationships among individual characteristics, perceived hazard characteristics, and affective response to the risk-in this instance, anger at managing agencies for not having done more to manage flood risks. Although the RISP model proposes the general causal ordering of the variables as listed above, this analysis is generally exploratory, attempting to find more microscopic patterns by working from the anger variable back to its proposed precursors, concentrating on potential roles for causal attributions. So the fourth (RQ4) research question focuses our exploration first on the relationships between anger and the component variables of perceived hazard characteristics and of individual characteristics.

The perceived hazard characteristics predictor variables in Table 4 show that residents who have less general trust in managing agencies were a little more likely to be angry with agencies in charge of managing the flood risk (beta $=-.10, p \leq .001$ ), as were people who judged there to be a greater risk of harm from river flooding in the future (the Probability $\times$ Severity measure, beta $=.25, p \leq .001)$. Among the five attribution variables, two correlate significantly with anger: Those who ascribe the flooding losses to poor government management are more likely to feel anger at the agencies (beta $=.15, p \leq .01$ ), whereas those who believe that people who live near the river are responsible for their own fate are less likely to feel this anger (beta $=-.15, p \leq .01$ ). These results seem generally consistent with 
processes that might intensify anger under these conditions. Less apparent, though, is the reason for a little more anger among those who feel a greater sense of personal efficacy in regard to doing something about the flooding (beta $=.12, p \leq .01$ ). Also notable from the standpoint of the RISP model is that the block of attribution variables does account for a significant increment of the variance in anger $(7 \%, p \leq .001)$ over and above the variance $(11 \%, p \leq .001)$ accounted for by the three primary components of perceived hazard characteristics in this analysis: trust, efficacy, and risk judgment. In all, perceived hazard characteristics, with the addition of attributions, account for $18 \%(p \leq .001)$ of the variance in anger. The block of individual/study characteristics variables accounts for $8 \%(p \leq .001)$ of the variance in anger $\left(6 \%, p \leq .01\right.$, if interview wave is excluded from the set). ${ }^{5}$

The final research question (RQ5) examined the relationships that causal attributions have with other components of perceived hazard characteristics and with the individual characteristics variables. Because only two attributions related significantly to anger, this analysis continues by concentrating primarily on those two variables.

Those who have more trust in government agencies are a little less likely to attribute the harm from the flooding to poor agency management (beta = $-.12, p \leq .05)$, a result consistent with the meaning of that attribution. Relationships among the attribution variables show that ascribing the flooding losses to poor government management is associated with another external attribution related to governmental management, urban development upstream (beta $=.31, p \leq .001$ ). To a much lesser extent, blaming poor government management is also associated with blaming global warming (beta $=.10, p \leq .05$ ). Those who blame people living near the river for their own fate also tend to attribute the flooding losses to bad luck or chance (beta $=.18, p \leq .001)$. The block of individual/study characteristics predictors account for a nonsignificant $3 \%$ of the variance in the attribution to poor government management, but a significant $8 \%(p \leq .001)$ of the variance in attribution to those living near the river. ${ }^{6}$

\section{Discussion}

Consistent with the model, residents of the Menomonee River watershed who had greater capacity to seek and process the risk information, and those who sensed a greater gap between what they knew about the flood risks and what they needed to know (information insufficiency), sought and processed the information more actively. It is noteworthy that those who had higher 
Table 4

Regressions of Anger and Causal Attributions (standardized regression coefficients [betas] except where noted)

\begin{tabular}{|c|c|c|c|}
\hline \multirow{2}{*}{$\begin{array}{l}\text { Dependent: } \\
\text { Predictor }\end{array}$} & \multicolumn{2}{|c|}{ Attributions for flood losses } & \multirow[b]{2}{*}{$\begin{array}{c}\text { Anger toward } \\
\text { managing } \\
\text { agencies }\end{array}$} \\
\hline & $\begin{array}{l}\text { External: Poor } \\
\text { government } \\
\text { management }\end{array}$ & $\begin{array}{l}\text { Internal: People } \\
\text { living near river } \\
\text { responsible for } \\
\text { own losses }\end{array}$ & \\
\hline Individual/study characteristics $\Delta R^{2}$ & .03 & $.08 * * *$ & $.08 * * *$ \\
\hline \multicolumn{4}{|l|}{ Perceived hazard characteristics } \\
\hline Trust in management agencies & $-.12 *$ & -.02 & $-.10 * * *$ \\
\hline Personal efficacy & .09 & -.03 & $.12 * *$ \\
\hline Risk judgment & .09 & -.08 & $.25^{* * *}$ \\
\hline$\Delta R^{2}$ & $.05 * * *$ & .01 & $.11 * * *$ \\
\hline \multicolumn{4}{|l|}{ Causal attributions } \\
\hline Bad luck or chance & -.09 & $.18 * * *$ & .09 \\
\hline Global warming & $.10 *$ & -.09 & .02 \\
\hline Urban development upstream & $.31 * * *$ & .02 & -.01 \\
\hline Poor government management & & -.06 & $.15^{* *}$ \\
\hline $\begin{array}{l}\text { People living near river } \\
\text { responsible for own losses }\end{array}$ & -.06 & & $-.15^{* *}$ \\
\hline$\Delta R^{2}$ & $.12 * * *$ & $.04 * *$ & $.07 * * *$ \\
\hline Multiple $R$ & .45 & .37 & .50 \\
\hline Adjusted $R^{2}$ & $.16^{* * *}$ & $.10 * * *$ & $.21 * * *$ \\
\hline ANOVA & $F_{17,383}=5.59$ & $F_{17,383}=3.49$ & $F_{18,382}=7.01$ \\
\hline
\end{tabular}

levels of current knowledge and those with higher levels of formal education also had greater capacity to seek and process the information. The entire set of individual characteristics variables had, as a block, a significant impact on capacity. These results are consistent with the roles of these variables in the RISP model.

Channel beliefs, however, remained weaker and somewhat inconsistent predictors of seeking and processing risk information. One explanation may be that channel beliefs might, as the RISP model actually suggests, better predict seeking and processing through interactions with capacity and motivation variables, rather than as direct effects.

The combination of two other factors may also predict a stronger effect of channel beliefs on processing than on seeking. Chaffee (1986) argues that individuals engage in a cost/benefit analysis when they choose 
information channels. That is, they opt into channels that offer some combination of information relevance (benefit) and accessibility (cost). While relevance would dominate that equation in an ideal world, cost may routinely trump relevance in the real world. For example, we may believe that scientists will be the best sources of information about the risks of flooding, but if we know little about how to "find" the relevant scientific information in the world around us, then we may default to a more accessible (but potentially less relevant) channel. In an environment where cost trumps relevance as a channel selection mechanism, channel beliefs should have much more of an impact on information processing than on information seeking. Further analysis should examine these possibilities. It is also likely that channel beliefs might benefit from some reconceptualization or new measurement strategies, for example, as outcome beliefs, based on Ajzen's (1988) concept of behavioral beliefs.

Consistent with the model, anger and informational subjective norms related positively, albeit somewhat weakly, to information insufficiency. However, both variables, but especially informational subjective norms, had more direct relationships with effortful seeking and processing of flood risk information. These results suggest that the model might benefit from considering these factors as motivations for seeking and processing that are alternative or complementary to information insufficiency. Better measures, especially for anger, might reveal stronger relationships.

The amount of anger that watershed residents had toward managing agencies did seem to play a key role in the study, suggesting that anger can take its place among the affective response variables in the model. Along with its potential effect in motivating risk information seeking (and apparently other socially active behaviors as well), anger was associated with the entire set of risk perception (perceived hazard characteristics) variables in this study. Those who were angrier with the agencies perceived greater future risk from flooding and had somewhat less trust in the agencies. They also felt more efficacious themselves in dealing with the flooding, a result that calls for more research. Consistent with Lazarus's (2006) appraisal theory, one possibility is that people who felt that they themselves had some ability to do something about the flooding (possibly in concert with others) also believed that agencies were not doing what they could to control the risk, leaving them waiting in vain. Thus, these individuals might have become angry with the agencies.

In general, these three risk perception variables (risk judgment, trust, efficacy) accounted for $11 \%$ of the variance in anger. If one adds causal attributions to the set, the group accounts for $18 \%$ of the variance in anger. 
Thus, further research seems warranted into the role of causal attributions as an element of risk perception (perceived hazard characteristics).

Not all attribution measures used in this analysis correlated with anger. Perhaps some of the potential causal agents (bad luck, global warming, and urban development upstream) seemed to respondents too unpredictable or too far removed from actual responsibility. However, those who ascribed the flood damage to poor government management (external attribution) were angrier with the agencies, and those who believed that those living near the river were responsible for their own fate (internal attribution) were less angry with the agencies. Those who lived in the floodplain were less likely to ascribe the internal attribution to the flood damage (i.e., less likely to blame themselves or those like them). In general, these results seem to be consistent with attribution theory, especially as applied to the model.

\section{Conclusion}

In general, the RISP model seems applicable to the flood risk context. More generally, it seems to help describe the public's risk communication activity when risks become public issues and not just private concerns.

Anger, one of those affective reactions much on display in public risk negotiations, was a main focus in this analysis. Anger clearly seems to play a role in individuals' judgments, not only by influencing perceptions of how much information they need to help them make judgments about flood risks, but also by influencing decisions about the information seeking and processing strategies they need to employ to fill that information gap. As with other potentially strong emotions, such as fear and worry, higher levels of anger, then, appear to produce more determined, more effortful information gathering on the part of individuals.

But that effort does not take place in the absence of cognitive drivers. These and previous analyses using the RISP model indicate that cognitions and affect interact in complex, but occasionally predictable ways to influence information gathering and processing. Other models have been similarly illuminating on this score-Witte's (1994) Extended Parallel Process Model is one - and it will be important for risk communication researchers to continue to look for those interactions.

In many aspects, the RISP model is a work in progress. It invites researchers to propose, test, explore, and improve its various measures, concepts, and relationships. For example, using the RISP model as a base, this 
study explored the potential role of causal attribution in risk perception, examined anger as an affective response to risk, and further extended the application of the RISP model to impersonal risks. Research into risk perception and communication could benefit from a better understanding of the dynamics of anger and attributions.

Informational subjective norms and capacity continue to play noteworthy roles in the ways individuals seek and process risk information. Further research is warranted into each of these concepts as well. Both also have implications for risk communication practice. For example, analyses of the RISP model to date suggest that risk information campaigns might prepare target markets for risk information by first publicizing how risk knowledge and its acquisition are the norms among target populations. It also appears that, to actively engage risk information, people need to feel they have the capacity to acquire and understand whatever information is necessary to (1) deal cognitively with a risk, (2) manage an emotional response to it, or (3) meet normative expectations about what they should know about the risk. ${ }^{7}$ This perceived (self-reported) capacity is associated positively with formal education and with knowledge the individual already possesses about the risk. Thus, risk communicators may need to make special efforts to make risk information accessible and understandable to less educated audiences and to those who do not know much, if anything, about the risk. These initiatives might include public education programs designed to improve the capacity various audiences have to get and evaluate risk information. Presumably, people who become frustrated when trying to obtain useful risk information may abandon the effort.

Overall, the RISP model helps remind researchers and practitioners of the importance of an audience-based perspective on risk communication. In general, that means understanding how nonexperts evaluate risk information, how they use information to make decisions about risk, and generally providing audience members with the information they need rather than giving them only what the experts feel they should have (Griffin, et al., 1999).

\section{Notes}

1. Early in 1999, a regional agency held several meetings to elicit comments and suggestions from the public as plans were developed to reduce future flooding and to improve the river and its watershed. One plan called for the use of conservation easements along the 
waterway, which would prevent development on those parcels, thus allowing the land to continue to filter rainwater and reduce the risk of floods. This plan was criticized because it would have eliminated several north side parks. The agency also proposed demolishing businesses and homes in the floodplain and constructing detention ponds, that is, ponds that would divert overflow storm water from the river and hold it until the water levels subside. (Retention ponds, in contrast, hold at least some water indefinitely.) In late 1999, the governor of Wisconsin established a regional task force, itself somewhat controversial, to study flooding in the Menomonee River watershed, and in 2000 a committee of the Milwaukee County board endorsed the creation of detention ponds. One such pond has since been constructed on county-owned land.

2. Other descriptions of anger include the following: Anger involves both reproach and an undesirable outcome (Ortony, Clore, \& Collins, 1988); Anger is essentially a judgmental emotion, a perception of an offense (Solomon, 1984); Anger is elicitation of one or more aggressive plans by the combination of threat appraisal and coping processes (Rubin, 1986).

3. It is possible that the relationships between affect and risk perceptions are a two-way street. Individuals, especially when they need to make fast risk judgments, might rely on their initial affective response to a risk to interpret it, a phenomenon dubbed the "affect heuristic" (Slovic, Peters, Finucane, \& MacGregor, 2005). According to the affect heuristic, people may judge the risks and benefits of hazards by accessing a pool of positive and negative feelings they associate with the hazards (Finucane, Alhakami, Slovic, \& Johnson, 2000). Lerner and Keltner (2001), for example, found that fearful people tended to make risk-averse choices and perceive higher risk, whereas angry people expressed optimistic risk judgments and were likely to make risk-seeking choices.

4. Despite the low reliability of a number of the factors and summed indexes in the study (and of the "validity cues" channel beliefs factor in particular), we decided to use these composites so as to be consistent with other studies using the same model and measures. Attempts to improve measures for the RISP model (e.g., by adding more relevant items, reconceptualizing "channel beliefs") should continue.

5. There were statistically significant results among the individual/study characteristics variables. Residents of the Menomonee River watershed had, in general, become a little more angry with the agencies over the year from the first to the second wave of interviews (beta = $.14, p \leq .01$ ), even though no new flooding occurred during that time. Men were also a little more angry than women (beta $=-.13, p \leq .01$ ).

6. There were statistically significant results among the individual/study characteristics variables. Minority group members are slightly less likely to blame government management agencies (beta $=-.10, p \leq .05$ ), and men are more likely than women to blame those who live near the river for their own fate (beta $=-.11, p \leq .05$ ). Those who live in the floodplain of the river are less likely than those living elsewhere in the watershed to blame themselves (beta = $-.13, p \leq .01$ ). Finally, residents of the watershed who are politically more conservative are more likely to spread the blame, believing that government agencies are at fault (beta $=.11$, $p \leq .05$ ), as are those who live in the floodplain (beta $=.14, p \leq .01$ ).

7. In some cases, of course, persons may want to avoid risk-related information, for example, in managing their fear of a threatening hazard under conditions of low perceived efficacy (e.g., Witte, 1994). 


\section{Appendix \\ Measures Used for Key Variables}

\begin{tabular}{|c|c|}
\hline Concept & $\begin{array}{l}\text { Measure } \\
\text { Except where indicated otherwise, items were answered using 5-point, } \\
\text { Likert-type scales, with missing data replaced with means. "Don't } \\
\text { know" responses were recoded to the midpoint "feel neutral" } \\
\text { response. }\end{array}$ \\
\hline $\begin{array}{l}\text { Information } \\
\text { seeking }\end{array}$ & $\begin{array}{l}\text { When it comes to the topic of Menomonee river flooding ... } \\
\text { I'm likely to go out of my way to get more information. } \\
\text { When the topic comes up, I try to learn more about it. } \\
\text { Reversed: } \\
\text { When this topic comes up, I'm likely to tune it out. } \\
\text { Gathering a lot of information on river flooding is a waste of time. } \\
\text { Whenever this topic comes up, I go out of my way to avoid learning } \\
\text { more about it. }\end{array}$ \\
\hline $\begin{array}{l}\text { Information } \\
\text { processing }\end{array}$ & $\begin{array}{l}\text { Systematic (high loaders): } \\
\text { After I encounter information about this topic, I am likely to stop } \\
\text { and think about it. } \\
\text { If I need to act on this matter, the more viewpoints I get the better. } \\
\text { After thinking about this topic, I have a broader understanding. } \\
\text { When I encounter information about this topic, I read or listen to } \\
\text { most of it, even though I may not agree with its perspective. } \\
\text { Heuristic (high loaders): } \\
\text { When I see or hear information about this topic, I rarely spend much } \\
\text { time thinking about it. } \\
\text { When I encounter information about river flooding, I focus on only a } \\
\text { few key points. } \\
\text { If I need to act on this matter, the advice of one expert is enough for } \\
\text { me. } \\
\text { There is far more information on this topic than I personally need. }\end{array}$ \\
\hline $\begin{array}{l}\text { Information } \\
\text { insufficiency }\end{array}$ & $\begin{array}{l}\text { Current knowledge: } \\
\text { Now, we would like you to rate your knowledge about this risk. } \\
\text { Please use a scale of zero to 100, where zero means knowing } \\
\text { nothing and } 100 \text { means knowing everything you could possibly } \\
\text { know about this topic. Using this scale, how much do you think } \\
\text { you currently know about Menomonee River flooding? } \\
\text { Sufficiency threshold: } \\
\text { Think of that same scale again. This time, we would like you to } \\
\text { estimate how much knowledge you would need to achieve an } \\
\text { understanding of Menomonee River flooding that is good enough } \\
\text { for your purposes? Of course, you might feel you need the same, } \\
\text { more, or possibly even less, information about this topic. Using a } \\
\text { scale of zero to 100, how much information would be sufficient } \\
\text { for you, that is, good enough for your purposes? }\end{array}$ \\
\hline
\end{tabular}

(continued) 


\section{Appendix (continued)}

\begin{tabular}{|c|c|}
\hline Concept & $\begin{array}{l}\text { Measure } \\
\text { Except where indicated otherwise, items were answered using 5-point, } \\
\text { Likert-type scales, with missing data replaced with means. "Don't } \\
\text { know" responses were recoded to the midpoint "feel neutral" } \\
\text { response. }\end{array}$ \\
\hline $\begin{array}{l}\text { Perceived } \\
\text { information } \\
\text { gathering } \\
\text { capacity }\end{array}$ & $\begin{array}{l}\text { If I wanted to get more information about Menomonee River } \\
\text { flooding... } \\
\text { I would know what questions to ask of the experts. } \\
\text { I would know where to go for more information. } \\
\text { I could readily take the time to gather any additional information I } \\
\text { might need. } \\
\text { Much of the information would be too technical for me to } \\
\text { understand. (Reverse coded.) } \\
\text { I would know how to separate fact from fiction. } \\
\text { I believe I could understand information on this topic if I make the } \\
\text { effort. }\end{array}$ \\
\hline Channel beliefs & $\begin{array}{l}\text { Media distort (high loaders): } \\
\text { The media often exaggerate and sensationalize the news. } \\
\text { News media often represent their own bias and interests. } \\
\text { The news stories are just a series of unconnected events that don't } \\
\text { add up to much. } \\
\text { Media provide validity cues (high loaders): } \\
\text { When the same information appears in many places, I'm more likely } \\
\text { to believe it. } \\
\text { Stories with statistics are more believable than those without. } \\
\text { Individual news items may seem like bits and pieces, but in the long } \\
\text { run they form a meaningful pattern. }\end{array}$ \\
\hline $\begin{array}{l}\text { Informational } \\
\text { subjective } \\
\text { norms }\end{array}$ & $\begin{array}{l}\text { People who are important to me think that I should stay on top of } \\
\text { information about [Menomonee] river flooding. }\end{array}$ \\
\hline Anger & $\begin{array}{l}\text { Please use a number from zero to ten, where zero means you have } \\
\text { "none of this feeling" and ten means you have "a lot of this feeling." } \\
\text { When you think about the Menomonee River, how much do you } \\
\text { feel... Angry that local agencies have not done more to minimize } \\
\text { flood risks? [Presented among other feelings.] }\end{array}$ \\
\hline Efficacy & $\begin{array}{l}\text { In my life, it would be easy for me to do something to minimize the } \\
\text { effects of river flooding. }\end{array}$ \\
\hline Trust & $\begin{array}{l}\text { I trust government to protect people from river flooding. } \\
\text { Government officials care about minimizing river flooding. } \\
\text { Government is doing a competent job of protecting people from } \\
\text { flooding caused by swollen rivers. }\end{array}$ \\
\hline
\end{tabular}

(continued) 


\section{Appendix (continued)}

Measure
Except where indicated otherwise, items were answered using 5-point,
Likert-type scales, with missing data replaced with means. "Don't
know" responses were recoded to the midpoint "feel neutral"
response.

\section{References}

Ajzen, I. (1988). Attitudes, personality, and behavior. Milton Keynes, UK: Open University Press. Bandura, A. (1986). Social foundations of thought and action. Englewood Cliffs, NJ: Prentice Hall.

Chaffee, S. H. (1996). Mass media and interpersonal channels: Competitive, convergent, or complementary? In G. Gumpert \& R. Cathcart (Eds.), InterMedia (3rd ed., pp. 62-80). New York: Oxford University Press.

Cohen, J., \& Cohen, P. (1983). Applied multiple regression/correlation analysis for the behavioral sciences (2nd ed.). Hillsdale, NJ: Lawrence Erlbaum.

Dijksterhuis, A., Bos, M. W., Nordgren, L. F., \& Van Baaren, R. B. (2006). On making the right choice: The deliberation-without-attention effect. Science, 311, 1005-1007.

Dunn, J. R., \& Schweitzer, M. E. (2005). Feeling and believing: The effects of emotion on trust. Journal of Personality and Social Psychology, 88, 736-748.

Eagly, A., \& Chaiken, S. (1993). The psychology of attitudes. Fort Worth, TX: Harcourt Brace Jovanovich. 
Earle, T. C., \& Cvetkovich, G. (1995). Social trust: Toward a cosmopolitan society. Westport, CT: Praeger.

Finucane, M. L., Alhakami, A., Slovic, P., \& Johnson, S. M. (2000). The affect heuristic in judgments of risks and benefits. Journal of Behavioral Decision Making, 13, 1-17.

Frijda, N. H. (1986). The emotions. Cambridge, England: Cambridge University Press.

Gregory, R., \& Mendelsohn, R. (1993). Perceived risk, dread, and benefits. Risk Analysis, 13, 259-264.

Gregory, J., \& Miller, S. (1998). Science in public: Communication, culture, and credibility. New York: Plenum.

Griffin, R. J. (1990). Energy in the eighties: Education, communication and the knowledge gap. Journalism Quarterly, 67, 554-566.

Griffin, R. J., Dunwoody, S., \& Neuwirth, K. (1999). Proposed model of the relationship of risk information seeking and processing to the development of preventive behaviors. Environmental Research, 80, S230-S245.

Griffin, R. J., Neuwirth, K., \& Dunwoody, S. (1998). Information sufficiency and risk communication. Paper presented to the 1998 annual convention of the Association for Education in Journalism and Mass Communication, Baltimore, MD.

Griffin, R. J., Neuwirth, K., Dunwoody, S., \& Giese, J. (2004). Information sufficiency and risk communication. Media Psychology, 6, 23-61.

Griffin, R. J., Neuwirth, K., Giese, J., \& Dunwoody, S. (2002). Linking the heuristic-systematic model and depth of processing. Communication Research, 29, 705-732.

Griffin, R. J., Powell, M., Dunwoody, S., Neuwirth, K., Clark, D., \& Novotny, V. (2004). Testing the robustness of a risk information processing model. Paper presented at the 2004 annual convention of the Association for Education in Journalism and Mass Communication, Toronto, Ontario, Canada.

Griffin, R. J., Yang, Z., Boerner, F., Bourassa, S., Darrah, T., Knurek, S., et al. (2005). Applying an information seeking and processing model to a study of communication about energy. Paper presented at the 2005 annual convention of the Association for Education in Journalism and Mass Communication, San Antonio, TX.

Groothuis, P. A., \& Miller, G. (1997). The role of social distrust in risk-benefit analysis: A study of the siting of a hazardous waste disposal facility. Journal of Risk and Uncertainty, 15, 241-257.

Kahlor, L., Dunwoody, S., \& Griffin, R. J. (2002). Attributions in explanations of risk estimates. Public Understanding of Science, 11, 243-257.

Kahlor, L., Dunwoody, S., Griffin, R. J., \& Neuwirth, K. (2006). Selecting and processing information about impersonal risk. Science Communication, 28, 163-194.

Kahlor, L., Dunwoody, S., Griffin, R. J., Neuwirth, K., \& Giese, J. (2003). Studying heuristicsystematic processing of risk communication. Risk Analysis, 23, 355-368.

Kasperson, R. E., Golding, D., \& Tuler, S. (1992). Social distrust as a factor in hazardous facilities and communicating risks. Journal of Social Issues, 48, 161-187.

Laird, F. N. (1989). The decline of deference: The political context of risk communication. Risk Analysis, 9, 543-550.

Lazarus, R. S. (2006). Emotions and interpersonal relationships: Toward a person-centered conceptualization of emotions and coping. Journal of Personality, 74, 9-46.

Lazarus, R. S., \& Smith, C. A. (1988). Knowledge and appraisal in the cognition-emotion relationship. Cognition and Emotion, 2, 281-300.

Lerner, J. S., \& Keltner, D. (2000). Fear, anger, and risk. Journal of Personality and Social Psychology, 81, 146-159. 
McComas, K. (2004). When even the 'best-laid' plans go wrong. EMBO Reports, 5(Suppl. 1), S61S65. Also available online at http://www.pubmedcentral.nih.gov/articlerender.fcgi?artid= 1299213

McGuire, W. J. (1974). Psychological motives and communication gratification. In J. G. Blumler \& E. Katz (Eds.), The uses of mass communications: Current perspectives on gratifications research (pp. 167-198). Beverly Hills, CA: Sage.

Nisbett, R., Borgida, E., Crandall, R., \& Reed, H. (1976). Popular induction: Information is not necessarily informative. In Carroll, J. S., \& Payne, J. (Eds.), Cognition and social behavior (pp. 113-133). Hillsdale, NJ: Erlbaum.

Novotny, V., Clark, D., Griffin, R. J., \& Booth, D. (2000). Risk-based urban watershed management under conflicting objectives. Paper presented at the First World Water Congress of the International Water Association, Paris, France.

Ortony, A., Clore, G. L., \& Collins, A. (1988). The cognitive structure of emotions. Cambridge, UK: Cambridge University Press.

Rubin, J. (1986). The emotion of anger: Some conceptual and theoretical issues. Professional Psychology: Research and Practice, 17, 115-124.

Siegrist, M., Cvetkovich, G., \& Roth, C. (2000). Salient value similarity, social trust, and risk/benefit perception. Risk Analysis, 20, 353-362.

Slovic, P. (1992). Perceptions of risk: Reflections on the psychometric paradigm. In S. Krimsky \& D. Golding (Eds.), Social theories of risk (pp. 117-152). Westport, CT: Praeger.

Slovic, P., Peters, E., Finucane, M. L., \& MacGregor, D. G. (2005). Affect, risk, and decision making. Health Psychology, 24, S35-S40.

Smith, C. A., \& Lazarus, R. S. (1990). Emotion and adaptation. In L. A. Pervin (Ed.), Handbook of personality: Theory and research (pp. 609-637). New York: Guilford Press.

Solomon, R. C. (1984). Getting angry: The Jamesian theory of emotion in anthropology. In R. A. Shweder \& R. A. LeVine (Eds.), Culture theory: Essays on mind, self, and emotion (pp. 238-254). Cambridge, UK: Cambridge University Press.

Tichenor, P., Donohue, G., \& Olien, C. (1970). Mass media flow and differential growth in knowledge. Public Opinion Quarterly, 34, 159-170.

Trumbo, C. W. (2002). Information processing and risk-perception: An adaptation of the heuristic-systematic model. Journal of Communication, 52, 367-382.

Viswanath, K., \& Finnegan, R. (1995). The knowledge gap hypothesis: Twenty-five years later. In B. Burleson (Ed.), Communication yearbook, 19 (pp. 187-228). Thousand Oaks, CA: Sage.

Weiner, B. (1983). Some methodological pitfalls in attributional research. Journal of Educational Psychology, 75, 530-543.

Weiner, B. (2000). Intrapersonal and interpersonal theories of motivation from an attributional perspective. Educational Psychology Review, 12, 1-14.

Witte, K. (1994). Fear control and danger control: A test of the Extended Parallel Process Model (EPPM). Communication Monograph, 61, 113-134.

Robert J. Griffin is professor and director of the Center for Mass Media Research in the Diederich College of Communication at Marquette University, Milwaukee, WI, where coauthors Boerner, Ortiz, and Yang earned their Master of Arts degrees in communication. His research interests include communication about environmental issues, energy, health, science, and risk. 
Zheng Yang is a PhD student in the Department of Communication at Cornell University, Ithaca, NY. She studies science, health, environmental, and risk communication.

Ellen ter Huurne is a doctoral candidate at the Department of Psychology and Communication of Health and Risk, University of Twente, Enschede, The Netherlands. Her current research focuses on public responses to risks and on risk-related information behavior.

Francesca Boerner is an investigator in an environmental and technology research group at the Research Center Juelich in Germany. She studies risk perception and risk communication related to health and environmental risks, especially pandemics, ultraviolet radiation, and genomics.

Sherry Ortiz is a clinical instructor in oral and maxillofacial radiography and digital imaging instruction to predoctoral dental students at Marquette University School of Dentistry, Milwaukee, WI.

Sharon Dunwoody is Evjue-Bascom Professor of Journalism and Mass Communication and associate dean for social studies in the graduate school at the University of Wisconsin-Madison. She studies the role of the mass media in the public understanding of science. 